\title{
OPTIMIZING PERINATAL OUTCOME IN HIGH RISK PREGNANCIES USING DOPPLER VELOCIMETRY
}

\author{
Savithri D. R ${ }^{1}$, Pallavi $R^{2}$, Reethu Varadarajan ${ }^{3}$, Veena B. $T^{4}$
}

${ }^{1}$ Associate Professor, Department of Obstetrics \& Gynaecology, Kempegowda Institute of Medical Sciences. ${ }^{2}$ Post Graduate, Department of Obstetrics \& Gynaecology, Kempegowda Institute of Medical Sciences. ${ }^{3}$ Assistant Professor, Department of Obstetrics \& Gynaecology, Kempegowda Institute of Medical Sciences. ${ }^{4}$ Assistant Professor, Department of Obstetrics \& Gynaecology, Kempegowda Institute of Medical Sciences.

\section{ABSTRACT}

\section{BACKGROUND}

High risk pregnancies poses a threat for fetoplacental vascular supply and are a risk for fetal growth retardation. Umbilical artery Doppler velocimetry is an important test among the invasive tests used for evaluating the fetal well-being. This study was taken to detect any abnormalities in fetoplacental unit and fetal circulation in high risk pregnancies, to identify the hypoxemic fetus and time the delivery before the occurrence of academia and to compare the perinatal outcome with doppler indices.

\section{STUDY DESIGN AND RESULTS}

Thirty (30) patients with gestational age at or beyond 32 weeks of gestation who belong to high-risk pregnancies were included in the study and were subjected to clinical examination, biochemical tests, ultrasound and colour Doppler study. They were serially followed up with ultrasound and color Doppler at 34 and 36 weeks respectively. Findings of USG and Doppler studies were correlated with the perinatal outcomes.

The uterine artery, umbilical artery and the Middle Cerebral Artery (MCA) Doppler indices for the corresponding gestational age were compared with the reference values. The middle cerebral artery Doppler index was considered abnormal, if the value was below the 5th percentile of previously published values for gestational age. A single cut off value (1.08) was used for Cerebroplacental Ratio (MCA PI/UA PI), above which the cerebro-placental ratio was considered normal and below which it was considered abnormal.

\section{CONCLUSIONS}

The degree of abnormality in Doppler indicates the degree of fetal compromise. Absent End Diastolic Flow (AEDF) represents the extreme form of altered velocity in the umbilical arteries and it represents the fetus at highest risk of hypoxia. Reverse End Diastolic Flow (REDF) is an ominous sign indicating that the vascular resistance has reached a point where the blood flow is reversed during diastole indicating acidotic fetus. The foetuses with abnormal wave forms suffer from chronic hypoxia and are usually growth retarded. They are at increased risk for hypoxia and acidemia. The present study shows that in the high-risk pregnancies, serial Doppler velocimetry helps the obstetrician to identify fetus at hypoxia and timely delivery preventing acidemia.

\section{KEYWORDS}

Doppler, High-Risk Pregnancy.

HOW TO CITE THIS ARTICLE: Savithri D. R, Pallavi R, Reethu Varadarajan, Veena B. T. “Optimizing Perinatal Outcome in High Risk Pregnancies Using Doppler Velocimetry." Journal of Evolution of Medical and Dental Sciences 2015; Vol. 4, Issue 95, November 26; Page: 16064-16068, DOI: 10.14260/jemds/2015/2346.

\section{INTRODUCTION}

High risk pregnancies like PIH, GDM, severe maternal anaemia, Rh negative patients, patients with connective tissue disorders are at high risk for fetoplacental insufficiency leading to fetal growth restriction. The main goals of antepartum fetal surveillance are to identify fetuses at increased risk for perinatal mortality and morbidity. Doppler ultrasound allows a noninvasive assessment of fetal haemodynamics.[1,2]

Financial or Other, Competing Interest: None.

Submission 14-10-2015, Peer Review 15-10-2015,

Acceptance 16-11-2015, Published 25-11-2015.

Corresponding Author:

Dr. Reethu Varadarajan,

\#55, $6^{\text {th }}$ Main Road

Chamarajpet-18,

Bangalore.

E-mail: reethu.nandeesh23@gmail.com

DOI:10.14260/jemds/2015/2346.
Doppler investigation of the umbilical arteries provides information concerning perfusion of the fetoplacental circulation, while Doppler study of fetal vessels detects the haemodynamic rearrangements that occur in response to fetal hypoxia.

Umbilical artery (UA) Doppler velocimetry is the most rigorously evaluated test among the noninvasive tests of fetal well-being.[3] Several authors have reported a low end diastolic velocity in the umbilical artery as a consequence of high flow resistance in capillaries of the terminal villi.

A meta-analysis of randomized controlled trials of UA Doppler velocimetry in high-risk pregnancies (Mainly pregnancies with associated pregnancy-induced hypertension and suspected IUGR) demonstrated that its use was associated with a trend towards reduction of perinatal mortality.[4] 
In response to prolonged fetal hypoxic stress, circulatory adaptation occurs resulting in redistribution of the cardiac output to provide a constant oxygen supply to the brain and other essential organs (i.e., heart and adrenal glands).[5,6]

This compensatory adjustment on which the brain sparing effect is based is associated with a rise in diastolic velocities in Doppler cerebral artery waveforms. ${ }^{[7]}$

This rise is considered a manifestation of cerebral vasodilatation, causing a decrease in Doppler indices such as the pulsatility index.[8,9] At cordocentesis, a significant correlation has been observed between hypoxemia in fetuses with IUGR and abnormal Middle Cerebral Artery (MCA) Pulsatility Index (PI). Recent studies indicate that the cerebroplacental ratio and pulsatility index of MCA and UA is the most sensitive Doppler index for predicting perinatal outcome in fetuses with IUGR.[10,11] In the majority of the severely growth retarded fetuses, sequential deterioration of arterial and venous Doppler precedes biophysical profile score deterioration.

At least one-third of fetuses show early signs of circulatory deregulation 1 week before biophysical profile deterioration, and in most cases Doppler deterioration preceded biophysical profile deterioration by 1 day.[12] This indicates the significance of Doppler study in these patients for early detection of fetal compromise. This study was an effort to establish the role of uterine artery, UA and MCA Doppler ultrasound in predicting adverse perinatal outcome in high risk pregnancies and also to determine the role of Doppler velocimetry in clinical management of such pregnancies.

\section{AIMS AND OBJECTIVES}

The aims and objectives of the present study includes (i) To detect any abnormalities in fetoplacental unit and fetal circulation in high risk pregnancies. (ii) To identify the hypoxaemic fetus and time the delivery before the occurrence of academia (iii) To compare the perinatal outcome and decrease the morbidity, thus optimizing fetal outcome.

\section{MATERIAL AND METHODS}

This study was carried out at KIMS College and Research Centre for a period of 2 years. Thirty (30) patients with gestational age at or beyond 32 weeks of gestation who belong to high-risk pregnancies like pregnancy induced hypertension, maternal anaemia, gestation diabetes mellitus, $\mathrm{Rh}$ negative pregnancy, connective tissue disorders in mother, recurrent pregnancy loss were included in the study. Routine clinical examination and necessary biochemical evaluation were done and subjected to ultrasound and colour Doppler ultrasonography.

Patients were serially followed with ultrasound and colour Doppler at 34 and 36 weeks respectively. Findings of USG and Doppler studies were correlated with the perinatal outcomes. The uterine artery, umbilical artery and the middle cerebral artery Doppler indices for the corresponding gestational age were compared with the reference values. The umbilical artery Doppler indices were considered abnormal if the value was above the 95th percentile of previously published values for gestational age. Hypoxia was defined when there is AEDF and acedemia is when there is REDF.
The middle cerebral artery Doppler index was considered abnormal if the value was below the 5th percentile of previously published values for gestational age. A single cut off value (1.08) was used for Cerebroplacental Ratio (MCA PI/UA PI), above which the cerebroplacental ratio was considered normal and below which it was considered abnormal. The change in vascular resistance is more marked in uterine artery closer to the placental implantation site and it has less sensitivity in third trimester. Hence, uterine artery Doppler is not of much significance.

The study included all high-risk pregnancies at or beyond 32 weeks, singleton pregnant women with good dates, subjects willing to give signed informed consent and available for followup. Fetuses with congenital anomalies, multiple pregnancies and patients with unreliable dates were excluded from the study.

\section{DESIGN}

The patients were explained about the non-invasive/ atraumatic nature of the procedure. Synthetic ultragel was applied liberally over the abdomen to get a good acoustic coupling. Philips HD 11XE Colour Doppler ultrasound machine with a convex transducer of 2-5 MHz frequency was used. Doppler wave form was obtained after localizing the vessels by B mode real time scanner. Pulsed Doppler was used to get the Doppler signals after localizing the vessels. The maximum Doppler shift frequencies were obtained and various ratios were calculated from each vessel. Doppler examination was done when fetus was in apneic state to avoid the influence of fetal respiration on Doppler signals.

\section{Identification of Various Arteries and their Criteria}

1. Uterine Artery: Colour Doppler facilitates identification of the uterine artery substantially. The uterine signal was obtained per abdomen by pointing the probe in the iliac fossa towards the lower para-cervical area. In the colour mode, the uterine artery is seen to cross the external iliac artery just after its origin from the internal iliac artery and this point was taken as the sampling point. Doppler wave forms were obtained. Values of S/D ratio, RI and PI $>95$ th percentile as per the Harrington et al. Doppler indices and persistent early diastolic notch is considered abnormal.

2. Umbilical Artery: Flow velocity waveforms from umbilical artery can be easily obtained. For this colour flow is not usually needed. Doppler signals can be acquired from different points in cord, usually from mid portion of cord. Values of S/D ratio, RI and PI $>95$ th percentile as per the Harrington et al. Doppler indices, presence of Absent End Diastolic Velocity (AEDV) and Reversed End Diastolic Velocity (REDV) were considered abnormal.

3. Middle Cerebral Artery (MCA): MCA was visualized in transverse axial view of fetal head at a slightly more caudal plane than the one used for BPD. PI and RI $<5$ th percentile as per the Harrington et al. Doppler indices were considered abnormal.

\section{OUTCOME CRITERIA}

Patients in study group were followed with serial ultrasound and colour Doppler at 32, 34 and 36 weeks respectively. 
Any abnormal Doppler indices were analysed and treated accordingly. Doppler US results were correlated with fetal perinatal outcome. If the babies were shifted to NICU, they were followed up till discharge.

\section{RESULTS}

About three-fourth of the cases were between 21 to 30 years with most being aged between 26-30 years constituting 40\% of the total cases. Majority of them were primigravida accounting for $43.33 \%$ of cases and two-third of the patients were booked at KIMS Hospital. Obesity was seen in $20 \%$ of the study population. More than half of the cases had hypertensive disorder of pregnancy as complicating factor. Table 1. shows the distribution of risk factors in the study.

Table 2. shows the distribution of Doppler velocimetry on uterine artery. Normal uterine artery doppler velocimetry is when S/D ratio is normal and abnormal is when S/D ratio is elevated (More than 95th percentile).

With abnormal uterine artery Doppler study, pregnant patients were at high risk of developing PIH, abruptio placentae, IUGR and oligoamnios. Table 3. shows the doppler velocimetry between $32-33+6$ weeks of gestation. Out of 30 patients studied between 32-33+6days of gestation, three

had AEDF and 5 had CPR ratio <1.08, ( 3 of 5 patients with CPR $<1.08$ had AEDF in umbilical artery). These findings suggesting fetal hypoxaemia. Hence, five patients were delivered. Doppler velocimetry in 5 patients showed elevated S/D ratio in umbilical artery and normal S/D ratio in middle cerebral artery, suggesting increased resistance in fetoplacental unit. Pregnancies were continued with close fetal surveillance.

Table 4. shows the doppler velocimetry between 34 to $35+6$ days of gestation. Of the 25 cases, one patient had AEDF and 3 patients had CPR ratio<1.08, Doppler changes suggesting of fetal hypoxaemia and pregnancy was terminated. In nine patients with increased S/D ratio in umbilical artery, pregnancies were terminated in view of other obstetric causes. Four patients had severe preeclampsia with impending symptoms and three patients with severe IUGR with oligoamnios were delivered. One pregnancy was terminated in view of fetal monitor showing persistent fetal bradycardia. In one patient with increased S/D ratio in umbilical artery and normal S/D ratio in middle cerebral artery, pregnancy was continued with close fetal surveillance. One patient with PPROM had normal Doppler velocimetry. Labour was induced and delivered. Twelve patients were delivered between gestational age of 34-35+6 days.

Table 5. shows doppler velocimetry between 36 to $37+6$ days of gestational age. Of the remaining 13 cases, one patient with AEDF and four patients with CPR of less than 1.08, four pregnancies were terminated.

Four patients had increased S/D ratio in umbilical artery. Of them three patients had isolated IUGR and one patient had severe PE. Hence, they were induced and delivered. In four patients, labour was induced at 37 weeks in view of associated high risk factors.

One patient with gestational HTN with blood pressure under control with umbilical artery Doppler being normal at 34 weeks and increased S/D ratio at 36 weeks came with reduced fetal movements at 38 weeks +1 day. Doppler done showed AEDF. Pregnancy was terminated.
Thirteen patients in the study population had Doppler velocimetry changes suggestive of fetal hypoxemia constituting $43.33 \%$. Table 6 . shows the distribution of abnormal Doppler velocimetry in study population.

Table 7. shows the gestational age at termination. Majority of them were terminated by LSCS to prevent neonatal complications. LSCS was done to expedite the delivery in patients with Doppler changes suggestive of hypoxaemia/severe IUGR and also during intrapartum fetal distress and failed induction. Most babies were born with the birth weight of $1-1.5 \mathrm{~kg}$ constituting $36.67 \%$ were shifted to NICU for preterm management. Lowest birth weight was of $1.1 \mathrm{~kg}$ and the maximum birth weight was $3.11 \mathrm{~kg}$. Four babies had low Apgar of $6 / 10$ and $7 / 10$ at $1^{\text {st }}$ and $5^{\text {th }}$ minute. Hence, low birth weight babies constituted $80 \%(n=24)$ of preterm and IUGR babies. Low birth weight babies were 13 and very low birth weight babies were 11 . Total preterm babies were 23 .

Almost $86.66 \%$ babies had good APGAR at birth. Babies who had low APGAR at first minute required ventilator support. Nineteen babies were shifted to NICU constituting $63.33 \%$ of total. Most of them were for pre-term management constituting $40 \%$. Most patients had complications such as preterm and hyperbilirubinaemia and RDS, hence ventilated. Of the five babies who required ventilatory support, four had low APGAR and one baby developed severe RDS. The newborns who required ventilator support were those who had Doppler changes such as absent end diastolic flow in umbilical artery and Apgar at first minute was $6 / 10$ and $5^{\text {th }}$ minute was $7 / 10$. Pregnancies with CPR less than 1.08 during Doppler study when delivered, babies had Apgar of 8/10 and $9 / 10$ at birth. They required NICU admission for preterm management and RDS.

Pregnancies with elevated S/D ratio in umbilical artery during Doppler study when delivered, babies had Apgar of $8 / 10$ and $9 / 10$ at birth and had few required NICU admission and had few neonatal complications. There were no neonatal deaths. Table No. 8 shows correlation of Doppler with perinatal outcome.

\section{DISCUSSION}

Thirty pregnancies with high risk factors were studied, who were followed up with Doppler velocimetry according to study protocol. Pregnancies which showed abnormal doppler such as AEDF and CPR less than 1.08 were terminated and those which showed elevated S/D ratio in umbilical artery were followed up and managed appropriately. The results were correlated with parameters of perinatal outcome. In my study with $\mathrm{n}=30$, the mean maternal age was 28.5 years. Doppler was abnormal in 13 patients between $32-33+6$ weeks of gestation, of which five were terminated due to abnormal Doppler findings such as AEDF and CPR less than 1.08 suggesting hypoxaemia. Five patients with abnormal S/D ratio in umbilical artery and MCA were followed with close fetal surveillance.

Doppler was abnormal in 12 patients between $34-35+6$ days of gestation. Three patients with Doppler velocimetry showing hypoxaemia were terminated. Remaining eight pregnancies who had only increased S/D ratio in umbilical artery were terminated in view of associated medical and obstetric complications such as impending eclampsia, severe 
IUGR with oligoamnios. One patient with persistent fetal bradycardia was noticed to have true knot in umbilical cord during LSCS. One with normal Doppler study had PPROM, hence was delivered.

Doppler was abnormal in eight patients between 36$37+6$ days of gestation. Four patients with Doppler velocimetry showing hypoxaemia were terminated. In other four patients with elevated S/D ratio in umbilical artery, pregnancies were terminated in view of associated medical and obstetric complications such as severe pre-eclampsia and severe IUGR. In four patients, labour was induced at 37 weeks in view of associated high risk factors. One patient with gestational HTN with umbilical artery Doppler being normal at 34 weeks and increased S/D ratio at 36 weeks came with reduced fetal movements at 38 weeks +1 day. Doppler done showed AEDF, hence pregnancy was terminated. Twenty six babies constituting $86.66 \%$ had good Apgar of 8/10 and 9/10 at birth. Five babies who required ventilatory support had low Apgar (4) and one baby developed severe RDS, hence ventilated. Eighty percent of neonates $(n=24)$ had birth weight of less than $2.5 \mathrm{~kg}$ constituting both IUGR and preterm, 23 babies (76\%) were preterm. Of the 30 neonates, 19 neonates were admitted to NICU for various complications. Most of them were for preterm management. There were no neonatal deaths.

\section{CONCLUSION}

The degree of abnormality in Doppler indicates the degree of fetal compromise. The hemodynamic changes picked up by Doppler occur in compensatory phase of growth restriction, where pregnancies can be terminated preventing acedemia. AEDV represents the extreme form of altered velocity in the umbilical arteries and it represents the fetus at highest risk of hypoxia. REDV is an ominous sign indicating that the vascular resistance has reached a point where the blood flow is reversed during diastole indicating acidotic fetus. The foetuses with abnormal wave forms suffer from chronic hypoxia and are usually growth retarded. They are at increased risk for hypoxia and academia.

The present study shows that in the high risk pregnancies, serial Doppler velocimetry helps the obstetrician to identify the fetus at risk of hypoxia and timely delivery prevents acidemia. This timely delivery of sick foetuses helps preventing perinatal mortality and decrease the morbidity, thus optimizing fetal outcome.

\section{REFERENCES}

1. Deane C, Harrington K. A practical approach to obtaining optimum Doppler signals. In: Harrington K, Campbell S, editors. A colour atlas of Doppler ultrasonography in obstetrics. London: Arnold, 1995: 35-46.

2. Fitzgerald DE, Drumm JE. Non-invasive measurement of human fetal circulation using ultrasound: A new method. BMJ 1977; 2:1450-1451.

3. Kok JH, den Ouden AL, Verloove-Vanhorick SP, Brand R. Outcome of very preterm small for gestational age infants: The first nine years of life. Br J Obstet Gynaecol 1998; 105:162-168.
4. Cohn HE, Sacks EI, Heyman MA, Rudolph AM. Cardiovasculas responses to hypoxemia and academia in fetal lambs. Am J Obstet Gynaecol 1974;120:817- 21.

5. Peeters LH, Sheldon RE, Jones MD, et al. Blood flow to fetal organs as a function of arterial oxygen content. Am J Obstet Gynecol 1979; 135:637-646.

6. Campbell S. Fetal growth. In: Nathanielz P, Beard R, eds. Fetal physiology and medicine. Bournemouth, United Kingdom: Saunders, 1974:271-300.

7. Arbeille PH, Roncin A, Berson M, Pourcelot L. Exploration of the fetal cerebral blood flow by duplex Doppler-Linear array system in normal and pathologica pregnancies. Ultrasound Med Biol 1987; 13: 329-332.

8. Waldimiroff JW, Wijingaard JAGW, Degani S, Noordam MJ, Eyck J, Tonge HM. Cerebral and umbilical arterial blood flow velocity waveforms in normal and growth retarded pregnancies. Obstet Gynaecol 1987; 69:705-709.

9. Gramellini D, Folli MC, Raboni S, Vadora E, Merialdi A. Cerebralumbilical Doppler ratio as a predictor of adverse perinatal outcome. Obstet Gyneacol 1992; 74:416-420.

10. Arias F. Accuracy of the middle cerebral to umbilical artery resistance index ratios in the prediction of perinatal outcome in patients at high risk for fetal and neonatal complications. Am J Obstet Gynaecol 1994; 171:1541-1545.

11. Bahado-singh RO, Kovanci E, Jeffres A, Utku OZ, Deren O, copel J et al. The Doppler cerebroplacental ratio and perinatal outcome in intrauterine growth restriction. Am J Obstet Gynaecol 1999; 180:750-756.

12. Baschat AA, Gem bruch U, Harman CR. The sequence of changes in the Doppler and Biophysical parameters as severe fetal growth restriction worsens. Ultrasound Obstet Gynaecol 2001; 18:571.

\begin{tabular}{|c|c|c|}
\hline Risk Factors & Number & Percentage \\
\hline Pregnancy-induced hypertension & 11 & 36.67 \\
\hline Isolated IUGR & 5 & 16.67 \\
\hline Oligoamnious with IUGR & 4 & 13.33 \\
\hline GDM with PIH & 2 & 6.67 \\
\hline Rh negative pregnancy & 2 & 6.67 \\
\hline Chronic hypertension & 2 & 6.67 \\
\hline Chronic HTN with superadded PE & 1 & 3.33 \\
\hline Recurrent pregnancy loss & 1 & 3.33 \\
\hline Severe maternal anaemia & 1 & 3.33 \\
\hline Overt DM & 1 & 3.33 \\
\hline Total & 30 & 100 \\
\hline
\end{tabular}

\begin{tabular}{|c|c|c|}
\hline $\begin{array}{c}\text { Gestational Age } \\
\text { (Weeks) }\end{array}$ & $\begin{array}{c}\text { Normal } \\
\text { S/D Ratio }\end{array}$ & $\begin{array}{c}\text { Abnormal High } \\
\text { S/D Ratio }\end{array}$ \\
\hline $32-33+6$ & 11 & 19 \\
\hline $34-35+6$ & 5 & 20 \\
\hline $36-37+6$ & 4 & 9 \\
\hline \multicolumn{2}{|c|}{ Table 2: Doppler Velocimetry } \\
on Uterine Artery \\
\hline
\end{tabular}




\begin{tabular}{|c|c|c|}
\hline Doppler & Normal & Abnormal \\
\hline 1. Umbilical artery & 22 & 8 \\
\hline S/D ratio( high) & 25 & 5 \\
\hline PI(high) & 25 & 5 \\
\hline AEDV & 0 & 3 \\
\hline REDV & 0 & 0 \\
\hline 2. MCA & 25 & 5 \\
\hline S/D ratio(low) & 25 & 5 \\
\hline PI & 25 & 5 \\
\hline CPR<1.08 & 25 & 5 \\
\hline Table 3: Doppler Velocimetry between \\
32-33+6 weeks of Gestation (n=30) \\
\hline
\end{tabular}

\begin{tabular}{|c|c|}
\hline Gestational Age in Weeks & Number \\
\hline $32-33+6$ & 5 \\
\hline $34-35+6$ & 3 \\
\hline $36-37+6$ & 4 \\
\hline 38 & 1 \\
\hline \multicolumn{2}{|c|}{ Total } \\
\hline \multicolumn{2}{|c|}{ Population } \\
\hline
\end{tabular}

\begin{tabular}{|c|c|c|}
\hline Doppler & Normal & Abnormal \\
\hline 1. Umbilical artery & 8 & 5 \\
\hline S/D ratio( high) & 9 & 4 \\
\hline PI(high) & 9 & 4 \\
\hline AEDV & - & 1 \\
\hline REDV & - & - \\
\hline MCA & 5 & 8 \\
\hline S/D ratio(low) & 9 & 4 \\
\hline PI & 9 & 4 \\
\hline CPR<1.08 & 9 & 4 \\
\hline \multicolumn{2}{|c|}{ Table 5: Doppler Velocimetry between 37+6 days of } \\
\hline
\end{tabular}

\begin{tabular}{|c|c|c|}
\hline Doppler & Normal & Abnormal \\
\hline 1. Umbilical artery & 15 & 10 \\
\hline S/D ratio( high) & 16 & 9 \\
\hline PI(high) & 16 & 9 \\
\hline AEDV & - & 1 \\
\hline REDV & - & - \\
\hline 2. MCA & 17 & 8 \\
\hline S/D ratio(low) & 20 & 5 \\
\hline PI & 20 & 5 \\
\hline $\mathrm{CPR}<1.08$ & 22 & 3 \\
\hline \multicolumn{3}{|c|}{$\begin{array}{c}\text { Table 4: Doppler Velocimetry between } \\
34 \text { to } 35+6 \text { days of Gestation }(n=25)\end{array}$} \\
\hline
\end{tabular}

\begin{tabular}{|c|c|c|}
\hline & Number & Percentage \\
\hline $32-33+6$ days & 5 & 16.67 \\
\hline $34-35+6$ days & 3 & 40 \\
\hline $36-37+6$ days & 4 & 40 \\
\hline $38-40$ weeks & 1 & 3.33 \\
\hline Total & $\mathbf{1 3}$ & $\mathbf{1 0 0}$ \\
\hline Table 7: Gestational Age at Termination \\
\hline
\end{tabular}

\begin{tabular}{|c|c|c|c|c|}
\hline $\begin{array}{c}\text { Gestational } \\
\text { Age } \\
\text { (weeks) }\end{array}$ & \multicolumn{2}{|c|}{$\begin{array}{c}\text { Doppler } \\
\text { Changes }\end{array}$} & $\begin{array}{c}\text { Apgar } \\
\text { Scoring }\end{array}$ & $\begin{array}{c}\text { Neonatal } \\
\text { Complications }\end{array}$ \\
\hline $32-33+6$ & AEDF & 3 & $6 / 10,7 / 10$ & On ventilator, RDS, NEC \\
\hline & CPR<1.08 & 2 & $8 / 10,9 / 10$ & RDS, NEC, TTP \\
\hline $34-35+6$ & AEDF & 1 & $6 / 10,7 / 10$ & On ventilator, RDS \\
\hline & CPR<1.08 & 2 & $8 / 10,9 / 10$ & Preterm, TTP \\
\hline & High S/D ratio & 9 & $8 / 10,9 / 10$ & RDS,TTP \\
\hline $36-37+6$ & AEDF & 1 & $8 / 10,9 / 10$ & RDS, TTP \\
\hline & CPR<1.08 & 3 & $8 / 10,9 / 10$ & - \\
\hline & High S/D ratio & 4 & $8 / 10,9 / 10$ & - \\
\hline & Normal & 4 & $8 / 10,9 / 10$ & - \\
\hline & AEDF & 1 & $8 / 10,9 / 10$ & \\
\hline $38+1$ & Table 8: Correlation of Doppler with Perinatal Outcome \\
\hline
\end{tabular}

